\title{
Short- and Long-term Effects of Sparingly Soluble Phosphates on Crop Production in Two Contrasting Nigerian Alfisols
}

\author{
E. A. Akinrinde ${ }^{1}$ and K. A. Okeleye ${ }^{2}$ \\ ${ }^{1}$ Department of Agronomy, University of Ibadan, Ibadan, Nigeria \\ ${ }^{2}$ Department of Crop Production, University of Agriculture, Abeokuta, Nigeria
}

\begin{abstract}
The effectiveness of Sokoto and Ogun rock phosphates (RP) as substitutes for the conventional phosphorus (P) fertilizer sources in the production of tomato (Lycopersicon esculentum) and okra (Hibiscus esculentus) were evaluated using single super-phosphate (SSP) as reference. Their residual effects were also investigated using rice (Oryzae sativa) and soybean (Glysine max). The two experiments were $2 \times 2 \times$ 4 factorial combinations with completely randomized design (CRD) involving two crops, two soils, three P-fertilizer sources and a control. The treatment combinations were replicated four times to give a total of 64 pots, each containing $5 \mathrm{~kg}$ of either a slightly acid ( $p \mathrm{H} \mathrm{6.3)}$ alfisol (Typic Paleudalf) A, from Abeokuta (rainforest ecological zone) or a medium acid ( $p \mathrm{H}$ 5.9) alfisol (Oxic Paleustalf) B, from Zaria (southern Guinea savanna zone). The soils represent a wide range of Nigerian soils with medium to low P-availability and cultivated to various food and economic crops. The rock phosphates (particularly SRP) were more efficient than SSP in soil A but had less than 50\% relative agronomic efficiency (RAE) in soil B, especially when tomato was the test crop. They also had higher RAE in soil A than in soil B when okra was grown, though the efficiency was not as high as that of the reference fertilizer. In the slightly acid alfisol (A), ORP was less efficient than SRP whereas it had $47.8 \%$ RAE compared with 34.9\% RAE for SRP in the medium acid soil. In the second cropping, the soil from the rainforest zone still produced greater biomass than soil B while soybean gave more biomass than rice. The results confirmed that, apart from crop species to be grown, organic matter and clay contents as well as $\mathrm{pH}$ of soils should be considered for efficient utilization of the sparingly soluble phosphates for both short- and long- term effects in crop production.
\end{abstract}

\section{Introduction}

Phosphorus (P) is an important limiting nutrient element in the production of vegetables, cereals and leguminous crops. It stimulates root growth, flower development and seed formation besides enhancing rapid and vigorous as well as early maturity in these crops. With inadequate $\mathrm{P}$ supply, leaves are often small in size and greenish red, reddish brown, purple or bronze-like colours while fruits and seeds are small and have reduced quality (Denton \& Swarup, 1981; Al-Wandawi, 1983). The occurrence of excess available P is rare in soils since it is often adsorbed, sometimes strongly through fixation by colloidal (inorganic clay and organic materials) complexes formed with Al, Fe and Ca. It can also be lost through erosion, leaching and crop removal (Aduayi \& Ekong, 1981).

Crops have become so expensive to grow that nutrient deficiencies should not be allowed to limit their yields. However, this goal is far from reality. The use of phosphatic fertilizers is beyond the reach of peasant farmers due to procurement difficulties, especially in developing countries of the world. This necessitates research to investigate alternative materials that can be used as $\mathrm{P}$ fertilizer sources. One of the possibilities is the direct use of sparingly soluble rock phosphates (RP). Yet, it is not all soils that are suitable for such direct applications (Obigbesan \& Akinrinde, 2000). The objective for this work was, therefore, to investigate the direct and residual effects of two rock phosphate materials, namely Ogun rock phosphate (ORP) and Sokoto rock phosphate (SRP) applied directly as Pfertilizer sources in sequential cropping of okra and tomato, as well as rice and soybean in two contrasting soils.

\section{Materials and methods}

Two soils, A and B, were used for the experiments. Soil A was a slightly acid alfisol (Typic Paleudalf) collected from Abeokuta in the rainforest zone of south-west Nigeria (Soil Survey Staff, 1975; Agboola \& Ogunkunle, 1993) while soil B was a medium acid alfisol (Oxic Paleustalf) collected from Zaria in the southern Guinea savanna zone of northern Nigeria (Soil Survey Staff, 1975; Akintunde et al., 2000). Their physical and chemical properties were determined using laboratory methods described by Udo \& Ogunwale (1981).

The soils were crushed, passed through a 2-mm sieve and $4 \mathrm{~kg}$ filled into 32 polyethylene bags for each soil type. A $2 \times 2 \times 2$ factorial completely randomized design with four replications was adopted, giving a total of 64 experimental pots. The treatments used were an absolute control and $100 \mathrm{mg} \mathrm{P}_{2} 0_{5} / \mathrm{kg}$ soil each of Ogun rock phosphate, ORP (31.4\% $\left.\mathrm{P}_{2} 0_{5}\right)$, Sokoto rock phosphate, SRP $\left(34.2 \% \mathrm{P}_{2} 0_{5}\right)$ and single super phosphate, SSP $\left(18 \% \mathrm{P}_{2} 0_{5}\right)$. Each fertilizer was thoroughly mixed with the soils, watered to 60\% field capacity (FC) and allowed to equilibrate for 3 days. Tomato (Lycopersicon esculentum var. Ibadan local) and okra (Hibiscus esculentus var. V-35) were planted as first crop followed by rice and soybean. Two seedlings of the test crops were allowed to grow in each pot for 10 weeks before the aerial portions (shoot, fruits and root) were harvested and weighed. Prior to this, however, the height of plants was measured and the leaves counted at 2, 4 and 6 weeks while flowers and fruits were counted at weekly intervals between the 7th and 10th weeks of growth.

In order to compare the residual effects of the P sources in the two soil types, the growth and forage yields of rice (Oryza sativa L.) and soybean (Glycine max) were also evaluated after air-drying and sieving of the first cropping 
soil, but only for a 7-week-growth-period. The use of rice and soybean was in conformity with the cropping practice of the farmers around the experimental soil locations. The relative agronomic efficiencies (RAE) of the P sources were computed as the ratios of the yield responses with test fertilizer (GRP-ground rock phosphate) to the respective yield responses of the reference (SSP) fertilizer at the same rate (100 $\mathrm{mg} \mathrm{P}_{2} \mathrm{O}_{5} / \mathrm{kg}$ soil), i.e.

RAE $=[(y G R P-y C O N T R O L / y S S P-y C O N T R O L) \times 100] \%$, where $y=$ yield.

In all cases, analysis of variance (ANOVA) was performed based on the completely randomized design, CRD (Steel \& Torrie, 1981), using the statistical analysis system (SAS, 1985) computer software. Treatment effects and the magnitude of interactions were determined and the F-LSD (Carmer \& Swanson, 1971) was used to detect differences between treatment means at $5 \%$ significant level.

\section{Results and discussion}

The soils investigated represent a wide range of Nigerian soils with medium to low acidity and P availability. They are soils on which a wide range of food and economic crops such as oil palm, kola nuts, cassava, yam, maize, sweet potato, tomato and okra are cultivated.

\section{Soil properties}

The physical and chemical properties of the soils are given in Table 1. The Typic Paleudalf (soil A) had a higher proportion of sand $(712 \mathrm{~g} / \mathrm{kg}$ ) than the Oxic Paleustalf (soil B) with $523 \mathrm{~g} / \mathrm{kg}$. On the other hand, soil B had higher silt $(354 \mathrm{~g} / \mathrm{kg}$ ) and clay $(114 \mathrm{~g} / \mathrm{kg})$ contents than soil A. Silt and clay contents of soil A were $214 \mathrm{~g} / \mathrm{kg}$ and $74 \mathrm{~g} / \mathrm{kg}$, respectively. The two soils were, however, sandy loam in texture. Soil A had higher $p H$ than soil B (i.e. 6.3 against 5.9). Soil A also had a higher available P than soil B. Based on the 6-20 mg/kg critical range (Agboola \& Adeoye, 1985), soil A could be said to be adequately furnished with available $P$ than soil B.

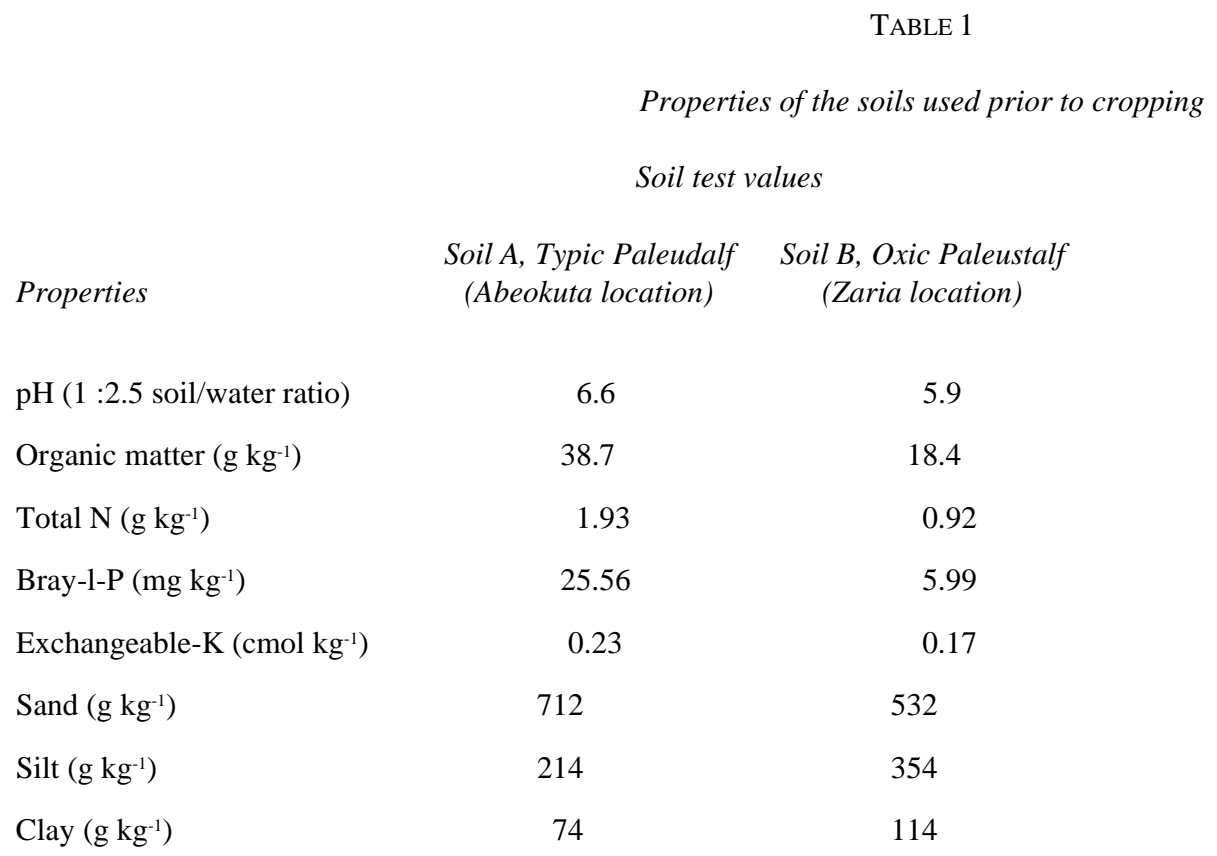

\section{First cropping}

Table 2 summarizes the effects of soil location or soil type, crop species and P fertilizer sources on plant height, numbers of leaves, flowers and fruits at successive growth stages. Soil type A from Abeokuta consistently produced crops with higher number of leaves, flowers and fruits, as well as taller plants than crops grown on soil B from Zaria. For instance, crops grown on soil A were $34.2 \mathrm{~cm}$ tall on the average compared with crops grown on soil B with 31.3 $\mathrm{cm}$ after 6 weeks of growth. Similarly, Soil A had an average of 4.6 and 1.2 flowers and fruits, respectively after 9 weeks of growth while crops grown on soil B had 4.7 and 0.9, respectively, at the same growth stage (Table 2). 
TABLE 2

Effects of experimental soil location, crop species and phosphorus fertilizer sources on plant growth and development in the first cropping

\begin{tabular}{|c|c|c|c|c|c|c|c|c|c|c|c|c|}
\hline \multirow[t]{3}{*}{ Treatment } & \multicolumn{3}{|c|}{ Plant height (cm) } & \multicolumn{3}{|c|}{$\begin{array}{l}\text { Number } \\
\text { of leaves }\end{array}$} & \multicolumn{3}{|c|}{$\begin{array}{l}\text { Number } \\
\text { of flowers }\end{array}$} & \multicolumn{3}{|c|}{$\begin{array}{l}\text { Number } \\
\text { of fruits }\end{array}$} \\
\hline & \multicolumn{12}{|c|}{ Weeks after planting } \\
\hline & 2 & 4 & 6 & 2 & 4 & 6 & 7 & 8 & 9 & 8 & 9 & 10 \\
\hline \multicolumn{13}{|l|}{ Soil location } \\
\hline Abeokuta & 7.4 & 13.7 & 34.2 & 6.2 & 13.9 & 28.8 & 3.0 & 4.0 & 4.6 & 16.1 & 1.2 & 1.6 \\
\hline Zaria . & 6.2 & 13.6 & 31.3 & 5.5 & 11.8 & 22.5 & 2.8 & 3.9 & 4.7 & 13.1 & 0.9 & 1.0 \\
\hline LSD & 0.5 & 1.2 & 2.2 & 0.4 & 1.0 & 1.9 & 0.8 & 0.9 & 1.3 & 2.7 & 0.3 & 0.3 \\
\hline \multicolumn{13}{|l|}{ Crop species } \\
\hline Tomato & 7.9 & 15.5 & 36.3 & 7.7 & 21.8 & 47.5 & 5.7 & 7.8 & 9.1 & 16.2 & 1.3 & 1.4 \\
\hline Okra & 5.6 & 11.8 & 29.2 & 4.0 & 3.8 & 3.8 & 0.2 & 0.1 & 0.1 & 12.9 & 0.8 & 1.2 \\
\hline LSD & 0.5 & 1.2 & 2.2 & 0.4 & 1.9 & 3.6 & 0.8 & 0.9 & 1.3 & 2.7 & 0.3 & 0.3 \\
\hline \multicolumn{13}{|c|}{ Phosphorus sources } \\
\hline Control & 5.9 & 9.7 & 27.4 & 5.8 & 10.3 & 19.6 & 2.3 & 3.2 & 4.1 & 10.8 & 0.9 & 1.0 \\
\hline ORP & 6.5 & 12.6 & 34.1 & 5.6 & 11.6 & 26.2 & 2.7 & 4.3 & 5.2 & 15.2 & 1.0 & 1.3 \\
\hline SRP & 6.9 & 15.2 & 35.4 & 6.0 & 13.6 & 26.9 & 3.1 & 3.5 & 4.3 & 15.3 & 1.1 & 1.4 \\
\hline SSP & 7.7 & 16.9 & 34.1 & 6.2 & 15.8 & 29.9 & 3.5 & 4.7 & 5.0 & 16.9 & 1.2 & 1.5 \\
\hline LSD & 0.7 & 1.5 & 2.9 & 0.6 & 2.5 & 5.0 & 1.3 & 1.4 & 2.4 & 4.0 & 0.6 & 0.6 \\
\hline
\end{tabular}

It is noteworthy that soil B did not support the growth of the crops as much as soil A. This is due to the fact that soil A was more fertile than soil B. Soil A had higher organic matter and other plant nutrient elements than soil B. The soil $p \mathrm{H}$ and clay content values were also more conducive for crop growth in soil A than in soil $\mathrm{B}$. This is in line with the report by Adepetu (1981) that rainforest soils generally have higher available $\mathrm{P}(8-15 \mathrm{mg} / \mathrm{kg})$ than most others, particularly from savanna ecological zones. There is also the possibility of higher sorption of applied phosphate ions in soil B than in soil A as a result of the higher clay contents of soil B. This is in agreement with the submission of Borggard (1986) that close linear relationship exists between clay content and phosphate sorption. Additionally, Table 2 exposes variations in the performance of the test crops arising from their morphological differences.

Tomato produced relatively more root mass than okra (Fig. 1), implying that it was able to forage for essential plant nutrients in general (P in particular) more than okra. According to Ojo (2001) higher plant uptake rate usually create a P-deficient zone around the roots due to slow $\mathrm{P}$ diffusion rate $\left(10^{-2}-10^{-15} \mathrm{~m}^{2}\right)$ in soils. The low availability of $\mathrm{P}$ in the bulk soil, therefore, limits plant uptake of the nutrients. As a result, plant root geometry and morphology are also important for maximizing P uptake. Lynch (1995) also noted that root system having high surface area to volume ratios will more effectively explore a large volume of soil than root systems with low surface area to volume ratio. 

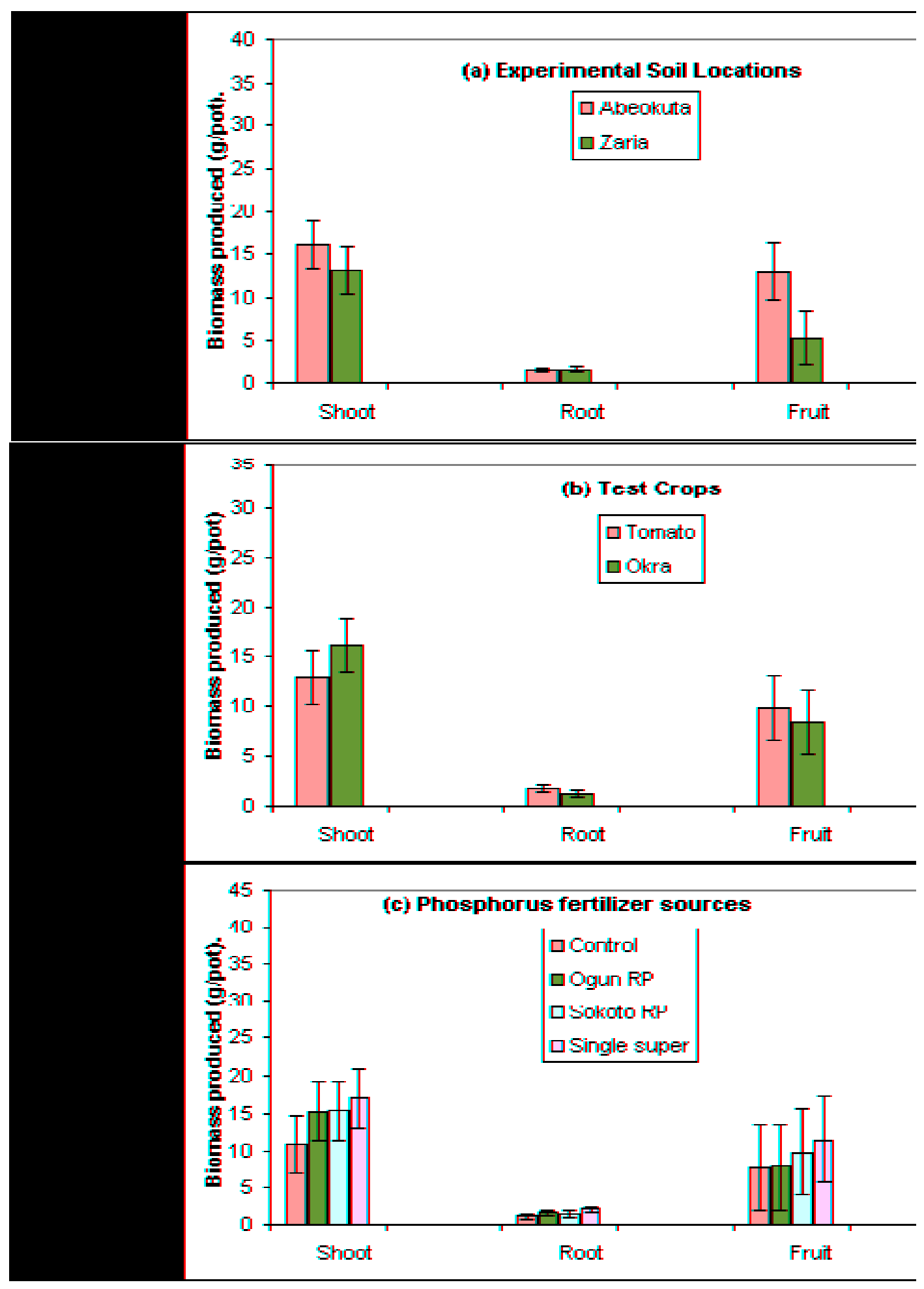

Fig. 1. Effects of experimental location soils, crop species and phosphorus fertilizer sources on biomass production

With regard to the $\mathrm{P}$ fertilizer treatments, the control plants had the least values for all the growth and yield component parameters (Table 2). The conventional soluble P fertilizer (SSP), however, gave the highest value in respect of the growth and yield component parameters. Among the rock phosphate fertilizer materials used, SRP proved to be generally more effective as $\mathrm{P}$ fertilizer than ORP (Table 2). This is in line with the submissions of Sobulo (1994) and Adediran and Sobulo (1998) that SRP increased crop yield and gave similar relative agronomic efficiency as SSP. Obigbesan \& Akinrinde (2000) also observed that SRP was more effective in weakly than strongly acid soils.

The influence of the experimental factors (soil type, crop type and P fertilizer source) on total biomass yield and fresh material partitioning into shoot, root and fruits are illustrated in Fig. 1. While soil A enhanced greater biomass production (30 g/pot) than soil B (20 g/pot), there was no significant difference in the total biomass yield for tomato and okra (a range of 25.0-27.0 g/pot). Nevertheless, SSP still proved to be the most effective P source while the 
untreated (control) plants had the least biomass yield. ORP and SRP were not very much different in their support for crop yield. The higher performance recorded by SSP in respect of growth and yield component parameters might be due to high solubility and ease of absorption of P (by the plants) from SSP relative to the other P sources.

The results of the effects of the various interactions between the experimental factors (soil type, crop type and $\mathrm{P}$ source) as they influenced the growth parameters are indicated in Table 3 . The P source * Soil * Crop interaction was significant, indicating that plant vigor and biomass yield differed at the various levels of each of the experimental factors. Thus, in line with the observed morphological differences between the test crops, shoot, root, fruit and biomass yields for tomato grown in soil A was significantly different from those of okra grown on the same soil (Table 3). Similarly, the effectiveness (as indicated by the estimated relative agronomic efficiency, RAE) of the ground rock phosphates with respect to biomass yields was different in the two soil types. For instance, ORP was $58.3 \%$ efficient in soil A, but only $45.6 \%$ efficient in soil B. In the same vein, SRP that was $149.2 \%$ as efficient as SSP in soil A was found to be just $11.3 \%$ as efficient in soil B. These RAE values are quite higher than the maximum of 100\% obtained for millet (Obigbesan \& Akinrinde, 2000).

TABLE 3

Effect of P-source*Soil * Crop interaction on relative yields (\%) of tomato and okra and relative agronomic efficiency, RAE (\%) of the phosphorus fertilizer sources in the first cropping.

\begin{tabular}{|c|c|c|c|c|c|c|c|c|}
\hline \multirow[t]{3}{*}{ Treatment } & \multirow{3}{*}{$\begin{array}{r}\text { Shoot } \\
(g / p o t)\end{array}$} & \multicolumn{7}{|c|}{ Biomass yield } \\
\hline & & \multicolumn{3}{|c|}{ Root } & \multicolumn{2}{|c|}{ Fruit } & \multicolumn{2}{|c|}{ Total } \\
\hline & & R. $Y$ & $(g / p o t)$ & R. $Y$ & $(g / p o t)$ & R. $Y$ & $(g / p o t)$ & R. $Y$ \\
\hline Control/Abeokuta/Tomato & 12.13 & - & 1.28 & - & 16.53 & - & 29.94 & - \\
\hline Control/Abeokuta/Okra & 11.15 & - & 0.90 & - & 6.40 & - & 18.45 & - \\
\hline Control/Zaria/Tomato & 8.10 & - & 1.13 & - & 4.18 & - & 13.41 & - \\
\hline Control/Zaria/Okra & 11.93 & - & 0.98 & - & 3.60 & - & 16.51 & - \\
\hline 0gun/RP/ Abeokuta/Tomato & 12.65 & 17.81 & 2.05 & 192.50 & 8.48 & 125.80 & 33.18 & 66.53 \\
\hline 0gun/RP/ Abeokuta/Okra & 17.80 & 51.01 & 1.15 & 30.12 & 15.85 & 277.90 & 34.80 & 98.61 \\
\hline 0gun/RP/Zaria/Tomato & 12.10 & 53.12 & 1.40 & 11.07 & 4.93 & 7.39 & 18.43 & 25.04 \\
\hline 0gun/RP/Zaria/Okra & 18.33 & 136.17 & 1.73 & 62.50 & 3.65 & 2.73 & 23.71 & 108.27 \\
\hline Sokoto/RP/Abeokuta/T omato & 20.60 & 290.07 & 1.78 & 125.00 & 18.25 & 17.00 & 40.63 & 219.51 \\
\hline Sokoto/RP/Abeokuta/Okra & 18.68 & 60.97 & 1.23 & 39.76 & 20.40 & 411.80 & 40.31 & 131.90 \\
\hline Sokoto/RP/Zaria/Tomato & 10.15 & 27.22 & 1.38 & 10.25 & 6.03 & 18.23 & 17.56 & 20.70 \\
\hline Sokoto/RP/Zaria/Okra & 12.88 & 20.21 & 1.13 & 125.00 & 4.38 & 42.62 & 18.39 & 28.27 \\
\hline Single super/Abeokuta/Tomato & 15.05 & 100.00 & 1.68 & 100.00 & 18.08 & 100.00 & 34.81 & 100.00 \\
\hline Single Super/Abeokuta/Okra & 23.50 & 100.00 & 1.73 & 100.00 & 9.80 & 100.00 & 35.03 & 100.00 \\
\hline Single super/Zaria/Tomato & 15.63 & 100.00 & 3.57 & 100.00 & 14.33 & 100.00 & 33.46 & 100.00 \\
\hline Single super/Zaria/Okra & 16.63 & 100.00 & 1.10 & 100.00 & 5.43 & 100.00 & 23.16 & 100.00 \\
\hline LSD & 0.64 & & 0.40 & & 5.81 & & 6.85 & \\
\hline
\end{tabular}

R.Y. = Relative yield (tomato or okra) $=$ [Yield of the crop on a particular soil type/ Maximum yield) $\times 100] \%$

RAE = Relative agronomic efficiency of the phosphorus $(\mathrm{P})$ sources $=[(\mathrm{yGRP}-\mathrm{yCONTROL} / \mathrm{ySSP}-\mathrm{yCONTROL}) \times 100] \%$, where $\mathrm{y}=\mathrm{yield}$.

\section{Second cropping}

In the second cropping, the P-source, soil type, crop type and the interactions of the three significantly influenced plant height and biomass yield. No interaction could, however, be established between P sources and either soil type or crop species. As in the first cropping, morphological differences between the alternative test crops (rice and soybean) caused significant differences in crop growth and yield on the soils (Table 4). The P source also produced significant differences in the height and fresh biomass yield but not in the dry matter production. SRP was $117.9 \%$ while ORP was $96.4 \%$ as efficient as SSP across the soils with regard to fresh biomass production (Table 4). With respect to dry matter production, however, SRP and ORP were $83.3 \%$ and $50 \%$ as efficient as SSP, respectively. The residual effect of $\mathrm{P}$ source * Soil * Crop interaction were also significant (Table 5). Soybean plants treated with SRP were $39.0 \mathrm{~cm}$ tall on the average when grown on soil A but only $34.0 \mathrm{~cm}$ tall when grown on soil B.

TABLE 4.

Effects of experimental location soils, crop species and phosphorus fertilizer sources on plant height, relative yields (\%) and relative agronomic efficiency, RAE (\%) in the second cropping. 


$\begin{array}{lr}\text { Plant } & \text { Fresh } \\ \text { height } & \text { biomass } \\ (\mathrm{cm}) & (\mathrm{g} / \mathrm{pot})\end{array}$

$\begin{array}{ll}\text { R.Y/RAE } & \text { Dry } \\ (\%) & \begin{array}{l}\text { biomass } \\ \text { (g/pot) }\end{array}\end{array}$

$$
\text { 37.3a }
$$

$7.0 \mathrm{~b}$

2.3

LSD

Crop species

Rice 35.6a

Soybean

LSD 2.3

Phosphorus fertilizer sources

Control

Ogun RP

Sokoto RP

Single super LSD

$5.3 \mathrm{~b}$
$34.6 \mathrm{a}$
1.8

$\begin{array}{lc}32.6 \mathrm{~b} & 7.4 \mathrm{~b} \\ 35.5 \mathrm{ab} & 10.1 \mathrm{ab} \\ 37.1 \mathrm{a} & 10.7 \mathrm{a} \\ 35.4 \mathrm{ab} & 10.2 \mathrm{a} \\ 3.7 & 2.8\end{array}$

$12.2 \mathrm{a}$
57.4

38.1
$13.9 \mathrm{a}$


$7.4 \mathrm{~b}$
$10.1 \mathrm{ab}$
$10.7 \mathrm{a}$
$10.2 \mathrm{a}$
2.8

$\begin{array}{ccr}100.0 & 3.6 \mathrm{a} & 100.0 \\ 2.0 \mathrm{~b} & 55.6 & \\ 1.8 & 0.5 & \\ & & \\ 1.1 \mathrm{~b} & 25.0 & \\ 100.04 .4 \mathrm{a} & 100.0 & \\ 0.5 & & \\ & & \\ & 2.4 \mathrm{a} & \\ 96.4 & 2.7 \mathrm{a} & 50.0 \\ 117.9 & 2.9 \mathrm{a} & 83.3 \\ 100.0 & 3.0 \mathrm{a} & 100.0 \\ & 0.9 & \end{array}$

R.Y. = Relative yield of test crops (tomato or okra) $=$ [Yield of the crop on a particular soil type/ Maximum yield) $\times 100] \%$

RAE $=$ Relative agronomic efficiency of the phosphorus $(\mathrm{P})$ sources $=[(\mathrm{yGRP}-\mathrm{yCONTROL} / \mathrm{ySSP}-\mathrm{yCONTROL}) \times 100] \%$, where $\mathrm{y}=$ yield.

TABLE 5

\begin{tabular}{|c|c|c|c|c|c|}
\hline Treatment & $\begin{array}{l}\text { Plant } \\
\text { height } \\
(\mathrm{cm})\end{array}$ & $\begin{array}{r}\text { Fresh } \\
\text { biomass } \\
(g / p o t)\end{array}$ & $\begin{array}{l}\text { R.Y/RAE } \\
(\%)\end{array}$ & $\begin{array}{l}\text { Dry } \\
\text { biomass } \\
\text { (g/pot) }\end{array}$ & $\begin{array}{l}\text { R.Y/RAE } \\
\text { (\%) }\end{array}$ \\
\hline Control / Abeokuta/ Rice & 33.1 & 5.6 & - & 1.3 & - \\
\hline Soybean & 35.1 & 12.5 & - & 5.4 & - \\
\hline Zaria & 34.2 & 3.6 & - & 0.7 & - \\
\hline Soybean & 27.9 & 7.9 & - & 2.4 & - \\
\hline Ogun RP / Abeokuta / Rice & 38.3 & 7.7 & 420.0 & 1.7 & 0.0 \\
\hline Soybean & 38.1 & 18.0 & 73.3 & 5.6 & 25.0 \\
\hline Zaria & 32.4 & 4.2 & 40.0 & 0.9 & 50.0 \\
\hline Soybean & 33.2 & 10.6 & 135.0 & 2.8 & 40.0 \\
\hline Sokoto RP / Abeokuta / Rice & 39.4 & 6.9 & 260.0 & 1.4 & 0.0 \\
\hline Soybean & 39.0 & 20.6 & 108.0 & 5.8 & 50.0 \\
\hline Rice & 35.1 & 3.4 & 13.3 & 0.7 & 0.0 \\
\hline Soybean & 34.8 & 11.7 & 190.0 & 3.7 & 130.0 \\
\hline Single super/Abeokuta/ Rice & 36.9 & 6.1 & 100.0 & 1.3 & 100.0 \\
\hline Soybean & 38.3 & 20.0 & 100.0 & 6.2 & 100.0 \\
\hline Zaria & 35.7 & 5.1 & 100.0 & 1.1 & 100.0 \\
\hline Soybean & 30.8 & 9.7 & 100.0 & 3.4 & 100.0 \\
\hline LSD & 3.7 & 2.8 & & 0.9 & \\
\hline
\end{tabular}

R.Y. = Relative yield of test crops (tomato or okra) $=$ [Yield of the crop on a particular soil type/ Maximum yield) $\times 100] \%$

RAE $=$ Relative agronomic efficiency of the phosphorus $(\mathrm{P})$ sources $=[(\mathrm{yGRP}-\mathrm{yCONTROL} / \mathrm{ySSP}-\mathrm{yCONTROL}) \times 100] \%$, where $\mathrm{y}=$ yield.

\section{Conclusion}

The benefit of the sparingly soluble rock phosphates (RP) is soil type dependent. Across the soils and particularly for the medium acid Oxic Paleustalf, the order of effectiveness of the P sources for the growth and yield of the test crops is SSP > SRP > ORP. However, on the slightly acid Typic Paleudalf the order was SRP $>$ SSP $>$ ORP.

Among other crops, tomato and okra are produced on sites where the experimental soils were collected. Information on the relative agronomic efficiency (RAE) of various RP for the growth of these crops on the different soil types could assist in their economic production such that each crop is grown only under the most conducive soil - RP situation. The significant interactions among the experimental factors confirm that, apart from crop species to be grown, soils' physico-chemical properties (e.g. organic matter and clay contents, as well as $\mathrm{pH}$ ) should be considered in the efficient utilization of the sparingly soluble phosphates. An economic analysis of the relative short- and longterm benefits of these phosphate fertilizers on field-grown crops would also be necessary. 


\section{References}

Adediran J. A. and Sobulo R. A. (1998). Agronomic evaluation of phosphorous fertilizer developed from Sokoto rock phosphate in Nigeria. Comm. Soil Sci. Pl. Anal. 29 (15 \& 16): 2415-2421.

Adepetu J. A (1981). Characteristic phosphorus sorption and its implication in soils of Ondo State of Nigeria. Trop. Agric. vet. Sci. J. 19 (3): 291-300.

Aduayi E. A. and Ekong E. E. (1981). General Agriculture and Soils. 62 pp.

Agboola A. A. and Adeoye G. O. (1985). Critical levels for soil $p \mathrm{H}$, available P, K, Zn and maize ear leaf content for $\mathrm{P}, \mathrm{Cu}$, and $\mathrm{Mn}$ in sedimentary soil of south-western Nigeria. Fert. Res. 6: 65- 71.

Agboola A. A and Ogunkunle A. O. (1993). Site characterization of Epemakinde, Ondo State, Nigeria. Technical Report on Land Development for Sustainable Agriculture in Africa. Bangkok, Thailand: IBSRAM/AFRICALAND Network. pp. 121-131.

Akintunde A. Y., Obigbesan G. O., Kim S. K. and Akinrinde E. A. (2000). Effects of Nitrogen rates on Grain Yield Response of Maize Varieties in Four Ecological Zones of Nigeria. Niger. J. Soil Sci. 12: 35-44.

Al-Wandawi H. (1983). Chemical Composition of Seeds of two Okra cultivars. J. Agric. F. Chem. 31 (6): 13551358.

Borggard O. K. (1986). Iron oxides in relation to phosphate adsorption by soils. Acta Agric. Scandinavia. 36: 107118.

Carmer S. G. and Swanson M. R. (1971). Detection of differences between means. A Monte Carlo Study of Five Pair wise Multiple Comparison Procedure. Agron. J. 63: 940-945.

Denton L. and Swarup V. (1981). Tomato cultivation and its potential in Nigeria. Acta Hort. 1981: 257-262.

Lynch J. (1995). Root architecture and plant productivity. Pl. Physiol. 109: 7-13.

Obigbesan G. O. and Akinrinde E. A. (2000). Evaluation of the performance of Nigeria Rock phosphates applied to millet in selected benchmark soils. Niger. J. Soil Sci. 12: 88-99.

Ojo O. D. (2001). Growth, development and yield of amaranth (Amaranthus cruentus L.) varieties in response to different sources of phophorus. (PhD Thesis.). University of Ibadan, Nigeria.

Sobulo R. A. (1994). Final report on Agro-mineral Projects Raw Materials Research and Development Council (RMRDC) and National Fertilizer Company of Nigeria (NAFCON). Port-Harcourt, Nigeria: RMRDC/NAFCON.

Soil Survey Staff (1975). Soil taxonomy: A Basic System of Soil Classification for Making and Interpreting Soil Survey. USDA Handbook 436. Washington, DC: U. S. Government Printing Office.

Statistical Analysis System (SAS) (1985). SAS user's guide: Statistics, 5th edn. Cary, NC: SAS Inst.

Steel R. G and Torrie J. H. (1981). Principles and procedures of Statistics. New York: McGraw-Hill Book Co.

Udo E. J. and Ogunwale J. A. (1981). Laboratory manual for the analysis of soil, plant and water samples. Ibadan, Nigeria: Department of Agronomy, University of Ibadan, Nigeria. 